\title{
The evaluation of antiretroviral treatment in HIV and hepatitis B virus (HBV) co-infected persons in Beijing, China, 2010-2018: a retrospective cohort study
}

\section{Peicheng Wang}

Tsinghua University School of Medicine

\section{Bingbing Guo}

Beijing University of Technology

Junfang Xu

Zhejiang University

Jason K Wang

Tsinghua University

Hongyan Lu

Beijing Center for Disease Control and Prevention

\section{Xiao Zhao}

Beijing Center for Disease Control and Prevention

\section{Qianyun Wang}

Tsinghua University School of Medicine

\section{Liangmin Gao}

Tsinghua University

\section{Jun Jing}

Tsinghua University

Feng Cheng ( $\nabla$ fcheng@mail.tsinghua.edu.cn )

Tsinghua University School of Medicine https://orcid.org/0000-0001-6105-1053

\section{Research article}

Keywords: Hepatitis B virus, HIV, Antiretroviral treatment, Clinical indicators, LTFU or death

Posted Date: November 14th, 2019

DOI: https://doi.org/10.21203/rs.2.17306/v1

License: (c) (i) This work is licensed under a Creative Commons Attribution 4.0 International License. Read Full License 


\section{Abstract}

There is limited long-term data on the effect of ART on clinical outcomes in HIV/HBV patients in China. The objective of this study was to understand the ART treatment effect and the factors associated with the loss to follow-up or death of HIV/HBV co-infected patients in the city of Beijing, China. Methods: This study examined clinical indicators for HIV mono-infected or HIV/HBV co-infected patients from Jan. 2010 to Sep. 2018. Included patients were followed for a mean duration of 34.5 months after ART. Covariance analysis for repeated measures was used to analyze the changes of clinical indicators; multivariate logistic regression and Cox model were used to analyze the influencing factors of the abnormal incidence of clinical indicators and the lost to follow-up or death in HIV patients. Results: A total of $841 \mathrm{HIV} / \mathrm{HBV}$ co-infected patients and $2000 \mathrm{HIV}$ patients were analyzed. Adherence was estimated to be $93 \%$ in all patients. At baseline, ALT, AST, Ols and APRI $\geq 0.5$ in HIV/HBV patients were higher, while the CD4 and CD4/CD8 ratio were lower. After ART treatment, the rate of $\mathrm{APRI} \geq 0.5(4.4 \%)$ were still higher in HIV/HBV patients and HBV coinfection affect the prevalence of $A P R I \geq 0.5(O R=2.745,95 \% \mathrm{Cl} 1.041-7.243)$. The variables related to LTFU or death in HIV patients were initial CD4 (HR=0.784, 95\% Cl 0.652-0.943), APRI $\geq 0.5$ (HR=4.647, 95\% Cl 1.331-16.227), Ols $(\mathrm{HR}=4.910,95 \% \mathrm{Cl} 2.352-10.247)$ and age $(\mathrm{HR}=1.336,95 \% \mathrm{Cl}$ 1.004-1.778). HBV coinfection was not associated with increased LTFU or overall mortality in HIV patients $(p>0.05)$. Conclusion: With good ART treatment and adherence rate, the clinical indicators were improved significantly in HIV/HBV co-infected patients. However, the incidence of hepatic fibrosis was higher in these patients.

\section{Introduction}

Liver diseases that are caused by the hepatitis B virus (HBV), including cirrhosis and hepatocellular carcinoma (HCC) $[1,2]$, have become increasingly important in patients infected with HIV as their life expectancy is getting longer with successful ART [3-5]. Worldwide, approximately 37 million people are infected with HIV and about 5-20\% are coinfected with HBV [6,7]. By the end of Sep. 2018, a total of 849,602 HIV patients were alive in China [8], 67.3\% of whom had received antiretroviral therapy (ART) treatment [9], and the prevalence of HIV and HBV co-infection was 8.7-14\% $[4,10]$. HIV and HBV shared transmission routes, including intravenous drug abuse, blood transfusion or blood products, sexual and mother-to-child transmission, whereas the immunodeficiency also caused by HIV enhances the likelihood of HBV persistence [1,2,7]. All these reasons lead to a gradual increase in the incidence of HIV/HBV coinfected patients.

Another reason may be related to hepatitis B vaccine which is an excellent intervention for preventing HBV infection $[1,2,11]$. At present, the hepatitis B vaccine vaccination rates in children under 5 years old remains above $90 \%$ in China, however, this rates in adults was fewer than 10\% [11-14]. The rate of effective vaccination against HBV was only $7.7 \%$ in HIV-infected patients in west China [15]. In addition, HBV vaccine response rates is only 20 to $70 \%$ in HIV infected adults [16]. So vaccination of HBV vaccine in HIV high-risk population may help to reduce the incidence of HIV/HBV co-infection.

Among HIV patients receiving ART treatment, HBV status shows no effect on virological failure $(\mathrm{OR}=0.93,95 \% \mathrm{Cl} 0.80$ 1.10) and $\mathrm{CD} 4$ counts $(\mathrm{OR}=0.93,95 \% \mathrm{Cl} 0.82-1.05)$ [4,17-20]. At present, more and more attention is being paid to mortality and hepatotoxicity in ART treatment for HIV/HBV co-infected patients. It is estimated that approximately 10$15 \%$ of mortalities in HIV patients globally are due to liver diseases, and about $25 \%$ of the liver deaths could be attributed to an HBV infection $[1,21,22]$. While the majority of those infected with HBV will naturally clear the infection, the risk of chronic HBV infection is estimated three- to six-fold higher in HIV patients than in those who are not infected with HIV [23-25]. ART induced liver toxicity is an additional concern in such patients. The incidence of hepatotoxicity in HIV patients taking ART is approximately 4.5-11\% [18,26,27]. Incidence of hepatic fibrosis (14.2\%) 
and cirrhosis (9.2\%) is more likely to occur in HIV/HBV co-infection patients [28-31] and the liver-related mortality in these patients was 8 times higher than that in HIV mono-infection patients [2,32]. Besides, HIV/HBV coinfection is a risk factor for in-hospital mortality [33], which also heightened overall mortality rates (Incidence Rate Ratio: 1.24) [3437].

CD4 T-cell counts prior to ART initiation, compliance to HIV therapy, economic level, regional differences and other related factors, can affect the therapeutic effect of HIV or HIV/HBV patients [7,28,38-40]. Especially in China, the economic level, health resource allocation, urban and rural factors among regions were greatly differentiated $[15,41]$. For example, the co-infection rate of HIV/HBV in west China was $14.4 \%$, and it is $47 \%$ among men who have sex with men (MSM) population in some areas of China $[7,15,42,43]$. While the impact of ART on clinical outcomes in HIV/HBV infected patients has been studied, little is known about its comparative performance or efficacy in conventional clinical settings in China [7]. By the end of Sep. 2018, the total mortality rate of the 19,567 HIV patients who had received ART treatment in Beijing was $0.92 \%$ (180 cases), the total lost to follow-up (LTFU) rate was $1.6 \%$ (304 cases), and about $4.3 \%$ of all HIV patients are co-infected with HBV. The present study assessed the effect of HBV co-infection on HIV clinical progression, virological and immunological responses in HIV patients receiving combination ART in Beijing, China. The results will reflect the therapeutic results of HIV/HBV patients in good ART environment, thus improving the willingness of this population to receive treatment.

\section{Methods}

\section{Study population}

Data was retrospectively collected from the Beijing Center for Diseases Prevention and Control (Beijing CDC). Since 2010, Beijing CDC database has recorded the comprehensive and reliable information of HIV patients, and all HIV/HBV patients started ART therapy from 2010. This study examined clinical characteristics and examination indicators for HIV mono-infected individuals or HIV/HBV co-infected patients after ART from Jan. 2010 to Sep. 2018. Patients with inconsistent or critical missing data were excluded.

In our study, 19,567 HIV patients received ART treatment in Beijing, of whom 81\% (15877 cases) were MSM. The numbers of HIV patients that were excluded: 1) HIV patients begin ART treatment before 2010 (757 cases); 2) age<18 year (221 cases); 3) ART treatment time is less than 6 months or the treatment time is uncertain (2751 cases); 4) HIV patients without HBV or HCV testing (433 cases); 5) HIV/HCV or HIV/HBV/HCV co-infected patients (315 cases). Chronic hepatitis B was defined as hepatitis B surface antigen seropositive on at least one occasion within the past 6 months [see Additional file 1].

HIV case report databases routinely record patients baseline and follow-up data including age, gender, marital status, route of HIV infection, opportunistic infections (OIs), ART regimen, CD4 count (Free testing twice a year), viral load (Free testing once a year), aspartate transaminase (AST), alanine aminotransferase (ALT), glucose (Glu), creatinine $(\mathrm{Cr})$, triglyceride (TG), total cholesterol (TC), platelet (PIt), and among other related variables.

Aspartate aminotransferase-to-Platelet Ratio Index (APRI) was categorized using validated cutoffs [28] : significant fibrosis (APRI $\geq 0.5$ ) and no significant fibrosis (APRI<0.5).ART adherence was reflected by the question of "Number of missed dose in recent 7 days", missed dose $\geq 1$ time (during follow-up, the HIV patient had at least one missed dose).

\section{Follow-up}


This study evaluated data from HIV patients and HIV/HBV co-infected patients between Jan. $1^{\text {st }} 2010$ and Sep. $30^{\text {th }}$ 2018. As per national guidelines at the time (Change of HARRT eligibility criteria in China: 2004-2007, CD 4 count< 200cells/ $\mu \mathrm{L} ; 2008-2011$, CD4 count $\leq 350$ cells/ $\mu \mathrm{L} ; 2012-2015$, CD4 count $<$ 500cells/ $\mu \mathrm{L} ; 2016-$ Now, immediate treatment), ART eligible individuals have three adherence counselling visits and a medical examination (include weight, height, vital signs, medication history, routine urine, blood tests, tests of the liver and kidney, CD4, VL, etc. ) prior to treatment initiation. Following ART initiation, patients were received in the clinic at 2, 4, 8, and 12-week as well as 3-month intervals, or more frequently in the case of pressing medical needs. In this study, we collected baseline data and follow-up variables for patients (the end of follow-up was Sep. 30 2018 ).

\section{Statistical analysis}

Mean \pm SD or median and interquartile ranges (Q) were used to describe numerical values, and percentage (\%) was employed to describe count data. Differences in baseline indicators among the two groups were examined using the Mann-Whitney $U$ test for non-parametrically distributed variables, and $t$ test for normally distributed variables. Categorial variables compared via the $\chi^{2}$ test. Analysis of covariance (ANCOVA) for repeated measures was used to analyze the changes of biochemical indicators in HIV/HBV co-infected patients. Multiple logistic regressions (variable selection implemented via stepwise approach) was used to analyze the influencing factors of the abnormal incidence of clinical indicators and Cox model was used to analyze the influencing factors of LTFU and death in HIV patients. Statistical analyses were conducted with SAS 9.4 software.

\section{Results}

A total of 2,841 HIV patients were included in our study: 2,000 patients were HIV mono-infected individuals and 841 patients were co-infected with HIV and HBV [see Additional file 1]. Demographic and baseline clinical characteristics of the sample are presented in Table 1. Median time interval (from diagnosis to anti-retro viral treatment), ALT and AST for HIV/HBV co-infected patients were statistically higher than those of HIV mono-infected patients. Baseline CD4 count, CD4/CD8 ratio, platelet and hemoglobin for HIV/HBV co-infected patients were statistically lower than those of of HIV mono-infected patients.

As shown in Table 1, the incidence of Ols (9.3\% vs 4.5\%) and APRI $\geq 0.5$ (7.9\% vs 1.8\%) in HIV/HBV co-infected patients was higher than that in HIV mono-infected patients $(P<0.05$,Table 1$)$.

\section{Table 1 Baseline characteristics of individuals included in the analysis}




\begin{tabular}{|c|c|c|c|}
\hline Variables & $\begin{array}{l}\text { HIV } \\
\text { mono-infected } \\
(\mathrm{n}=2000)\end{array}$ & $\begin{array}{l}\text { HIV/HBV } \\
\text { co-infected } \\
(\mathrm{n}=841) \\
\end{array}$ & $P$ value \\
\hline Age(years) & $33.0 \pm 10.7$ & $33.6 \pm 9.6$ & 0.143 \\
\hline $\operatorname{BMI}\left(\mathrm{kg} / \mathrm{m}^{2}\right)$ & $22.1 \pm 3.1$ & $22.0 \pm 3.2$ & 0.728 \\
\hline HIV diagnosis to ART initiation interval (months) & $1.1(0.5-4.8)$ & $1.4(0.6-4.7)$ & 0.011 \\
\hline CD4 count $($ cells $/ \mu \mathrm{L})$ & $302.0(188.0-427.5)$ & $261.0(143.6-378.0)$ & $<0.001$ \\
\hline CD4/CD8 ratio & $0.29(0.18-0.43)$ & $0.26(0.15-0.40)$ & 0.001 \\
\hline $\log _{10} \mathrm{VL}$ & $4.4 \pm 0.9$ & $4.4 \pm 0.8$ & 0.665 \\
\hline ALT (U/L) & $21.7(15.6-34.3)$ & $29.3(20.9-45.4)$ & $<0.001$ \\
\hline $\operatorname{AST}(\mathrm{U} / \mathrm{L})$ & $22.4(18.8-28.0)$ & $27.3(22.0-37.1)$ & $<0.001$ \\
\hline GLU (mmol/L) & $5.4 \pm 1.1$ & $5.3 \pm 1.2$ & 0.395 \\
\hline $\mathrm{TG}(\mathrm{mmol} / \mathrm{L})$ & $1.2(0.8-1.7)$ & $1.1(0.8-1.6)$ & 0.336 \\
\hline $\mathrm{TC}(\mathrm{mmol} / \mathrm{L})$ & $4.0 \pm 0.9$ & $4.0 \pm 0.9$ & 0.305 \\
\hline $\operatorname{Cr}(\mu \mathrm{mol} / \mathrm{L})$ & $71.7 \pm 13.0$ & $71.8 \pm 17.7$ & 0.831 \\
\hline Platelet $\left(\times 10^{9} / \mathrm{L}\right)$ & $208.3 \pm 58.8$ & $185.4 \pm 59.3$ & $<0.001$ \\
\hline Hemoglobin $(\mathrm{g} / \mathrm{L})$ & $147.2 \pm 18.1$ & $145.0 \pm 20.7$ & 0.009 \\
\hline $\mathrm{APRI} \geq 0.5(\%)$ & $34(1.8)$ & $62(7.9)$ & $<0.001$ \\
\hline \multicolumn{4}{|l|}{ Gender } \\
\hline Male & $1924(96.2)$ & $804(95.6)$ & 0.455 \\
\hline Female & $76(3.8)$ & $37(4.4)$ & \\
\hline \multicolumn{4}{|l|}{ Marital status } \\
\hline Single & $1408(70.4)$ & $555(66.0)$ & 0.948 \\
\hline Married or lives with partner & $465(23.3)$ & $244(29.0)$ & \\
\hline Others & $167(6.3)$ & $42(5.0)$ & \\
\hline \multicolumn{4}{|l|}{ Route of HIV infection } \\
\hline MSM & $1688(84.4)$ & $657(78.1)$ & $<0.001$ \\
\hline Hetero-sexual & $180(9.0)$ & $108(12.8)$ & \\
\hline Others or unknown & $132(6.6)$ & $76(9.0)$ & \\
\hline \multicolumn{4}{|l|}{ WHO stage when eligible for treatment } \\
\hline Stage 1 & $1539(77.0)$ & $563(66.9)$ & $<0.001$ \\
\hline Stage 2 & $239(12.0)$ & $122(14.5)$ & \\
\hline Stage $3 / 4$ & $222(11.0)$ & $156(18.6)$ & \\
\hline Opportunistic infections & $90(4.5)$ & $78(9.3)$ & $<0.001$ \\
\hline Missed dose $\geq 1$ time & $58(6.9)$ & $135(6.8)$ & 0.871 \\
\hline \multicolumn{4}{|l|}{ ART regimen } \\
\hline TDF & $1528(76.4)$ & $744(88.5)$ & $<0.001$ \\
\hline Second-line ART(LPV/r) & $77(3.9)$ & $45(5.4)$ & \\
\hline Others & 395 (19.8) & $52(6.2)$ & \\
\hline \multicolumn{4}{|l|}{ Year to enter ART treatment } \\
\hline 2010 & $19(2.2)$ & $24(1.2)$ & $<0.001$ \\
\hline 2011 & $62(7.4)$ & 77 (3.9) & \\
\hline 2012 & $73(8.7)$ & $129(6.5)$ & \\
\hline 2013 & $115(13.7)$ & $174(8.7)$ & \\
\hline Page & & & \\
\hline
\end{tabular}


The mean follow-up time for all patients was 34.5 months (SD: 24.2 months) per person in our study. The trajectory of key biochemical indicators plotted alongside ART treatment time is shown in Figure 1. The effect of baseline data on indicator changes during ART was adjusted by covariance analysis for repeated measures. Although, CD4 count levels were still statistically different between HIV mono-infected and HIV/HBV co-infected patients after 42 months of ART treatment $(P<0.05)$, no statistical difference was found between the two groups in the ART treatment effect after adjusting the influence of the baseline $\operatorname{CD} 4$ count $(P=0.3226$, Figure $1 A)$; In the course of treatment, the TG and TC means in HIV/HBV co-infected patients were lower than that in HIV mono-infected patients $\left(P_{g}<0.05\right.$, Figure $\left.1 \mathrm{~F}-\mathrm{G}\right)$. Besides, with the increase of ART treatment time, ALT in HIV/HBV patients was different from that in HIV patients at 3 months. And 3 months later, ALT gradually decreased and there was no difference with HIV mono-infected patients $\left(P_{g^{*} t}<0.001\right.$, Figure 1D). As for other indicators, AST, GLU, Cr, CD4/CD8 ratio, platelet and hemoglobin, the interaction between group and time effects was not significant $(P>0.05)$.

Of the $841 \mathrm{HIV} / \mathrm{HBV}$ co-infected patients treated (present mean duration for 34.5 months), $6.1 \%$ (45 cases) did not achieved CD $4 \geq 200$ cells/ $\mu \mathrm{L}$ (as of 30 Sep.2018, the data of patients' last clinical examination results) and $1.8 \%$ (13 cases) did not achieved VL $₫ 400$ copies/mL $₫$ which had no significant difference with HIV mono-infected patients $(P=0.7858 \times 0.3102)$. The rate of AST abnormalities (20.9\% vs $14.4 \%)$ and APRI $\geq 0.5(4.4 \%$ vs $1.0 \%)$ in $\mathrm{HIV} / \mathrm{HBV}$ coinfected patients was higher than that in HIV patients $(P<0.05)$. After ART treatment, there was no difference in the rate of $A L T>40 \mathrm{U} / \mathrm{L}, \mathrm{TC}>5.69 \mathrm{mmol} / \mathrm{L}, \mathrm{CD} 4 / \mathrm{CD} 8$ ratio $<0.30$, Ols, death and LTFU among the HIV/HBV co-infected and HIV mono-infected patients $(P>0.05$, Table 2$)$.

We further analyzed the influencing factors of adverse events in HIV patients. Initial CD4 count (OR=0.443), duration of ART (OR=0.456), initial Ols status $(\mathrm{Or}=4.240)$ and WHO stage $(\mathrm{OR}=1.485)$ were shown to be significantly associated with $\mathrm{CD} 4<200$ cells/ $\mu \mathrm{L}$ (Final follow-up results of patients up to Sep. 2018) in HIV patients $(P<0.05)$. Initial CD4 count $(\mathrm{OR}=0.568)$, initial $\mathrm{CD} 4 / \mathrm{CD} 8$ ratio $(\mathrm{OR}=0.149)$, duration of $\mathrm{ART}(\mathrm{OR}=0.466)$, and patients undergoing second-line ART $(\mathrm{OR}=1.952)$ were shown to be significantly associated with $\mathrm{CD} 4 / \mathrm{CD} 8$ ratio $<0.30$ in HIV patients $(P<0.05)$. Initial CD4 count $(\mathrm{OR}=0.743$ ) were shown to be significantly associated with $\mathrm{VL}>400$ copies $/ \mathrm{mL}$ in HIV patients $(P<0.05)$. Besides, HBV coinfection was no associated with CD4<200 cells/ $\mu \mathrm{L}, \mathrm{CD} 4 / \mathrm{CD} 8$ ratio $<0.30$ and VL $>400$ copies/mL in HIV patients $(p>0.05$, Table 2$)$.

Initial $A P R I \geq 0.5(O R=11.425)$ and HBV co-infection $(\mathrm{OR}=2.745)$ were shown to be significantly associated with APRI $\geq 0.5$ in HIV patients $(P<0.05$, Table 2$)$.

Table 2 Rate of adverse events and the risk factors for those in HIV patients 


\begin{tabular}{|c|c|c|c|c|c|c|c|c|c|c|}
\hline \multirow{9}{*}{$\begin{array}{l}\text { Rate } \\
\text { of } \\
\text { adverse } \\
\text { events }\end{array}$} & \multirow[t]{2}{*}{ Group } & \multirow{2}{*}{\multicolumn{2}{|c|}{$\begin{array}{l}\text { CD4<200 } \\
(\text { cells } / \mu \mathrm{L})\end{array}$}} & \multicolumn{2}{|l|}{$\mathrm{VL}>400$} & $\mathrm{ALT}>40$ & AST $>50$ & APRI $\geq 0.5$ & \multicolumn{2}{|c|}{$\mathrm{TC}>5.69$} \\
\hline & & & & (copies/) & & $(\mathrm{U} / \mathrm{L})$ & $(\mathrm{U} / \mathrm{L})$ & & \multicolumn{2}{|c|}{$(\mathrm{mmol} / \mathrm{L})$} \\
\hline & HIV & \multicolumn{2}{|c|}{$\begin{array}{l}108 / 1679 \\
(6.4)\end{array}$} & \multicolumn{2}{|c|}{$21 / 1636(1.3)$} & $\begin{array}{l}583 / 1026 \\
(56.8)\end{array}$ & $134 / 932$ & $7 / 671(1.0)$ & & $\begin{array}{l}1678 \\
.7)\end{array}$ \\
\hline & $\mathrm{HIV} / \mathrm{HBV}$ & \multicolumn{2}{|c|}{$45 / 733(6.1)$} & \multicolumn{2}{|c|}{ 13/711 (1.8) } & $\begin{array}{l}294 / 488 \\
(60.2)\end{array}$ & $\begin{array}{l}98 / 469 \\
(20.9)\end{array}$ & 15/341 (4.4) & \multicolumn{2}{|c|}{$\begin{array}{l}59 / 733 \\
(8.1)\end{array}$} \\
\hline & $P$ value & \multicolumn{2}{|c|}{0.7858} & \multicolumn{2}{|l|}{0.3102} & 0.2073 & 0.002 & 0.001 & \multicolumn{2}{|c|}{0.0893} \\
\hline & Group & \multicolumn{2}{|c|}{$\begin{array}{l}\text { CD4/CD8 } \\
\text { ratio }<0.30\end{array}$} & \multicolumn{2}{|l|}{ OIs } & Death & LTFU & \multicolumn{3}{|c|}{$\begin{array}{l}\text { Discontinued-- } \\
\text { treatment }\end{array}$} \\
\hline & HIV & \multicolumn{2}{|c|}{$\begin{array}{l}192 / 1674 \\
(11.5)\end{array}$} & $37(1.9)$ & & $6(0.3)$ & $14(0.7)$ & $29(1.5)$ & -- & \\
\hline & $\mathrm{HIV} / \mathrm{HBV}$ & $88 / 73$ & (12.0) & $25(3.0)$ & & $4(0.5)$ & $12(1.4)$ & $20(2.4)$ & -- & \\
\hline & $P$ value & 0.706 & & 0.068 & & 0.495 & 0.082 & 0.113 & -- & \\
\hline$\overline{R i s k}$ & & $\mathrm{CD}$ & $<200$ & ells $/ \mu \mathrm{L})$ & & & $\mathrm{CD} 4 / \mathrm{Cl}$ & D8 ratio $<0.30$ & & \\
\hline & Varia. & & OR $(9$ & $\%$ CI) & $P$ & Vari & les & OR (95\% CI) & & $\bar{P}$ \\
\hline & Initial & $\overline{\mathrm{CD} 4}$ & 0.44 & & $<0.001$ & Initic & $\overline{\mathrm{CD} 4}$ & $0.568(0.514,06$ & 6) & $<0.001$ \\
\hline $\begin{array}{l}\text { of } \\
\text { adverse } \\
\text { events }\end{array}$ & $\begin{array}{l}\text { Durat } \\
\text { ART }\end{array}$ & on of & $\begin{array}{l}0.368 \\
0.456 \\
(0.301\end{array}$ & (0.691) & 0.0002 & $\begin{array}{l}\text { Initi } \\
\text { CD44 }\end{array}$ & & $0.149(0.060,0.3$ & 70) & $<0.001$ \\
\hline & Initial & OIs & $\begin{array}{l}4.240 \\
(1.519\end{array}$ & 11.831) & 0.0426 & $\begin{array}{l}\text { Durc } \\
\text { ART }\end{array}$ & on of & $0.466(0.392,0.5$ & 55) & $<0.001$ \\
\hline & WHO & tage & $\begin{array}{l}1.485 \\
(1.162\end{array}$ & 1.897) & 0.0016 & $\begin{array}{l}\text { Secc } \\
\text { ART }\end{array}$ & d-line & $1.952(1.015,3.7$ & 54) & 0.0451 \\
\hline & $\begin{array}{l}\text { HBV } \\
\text { infec }\end{array}$ & & $\begin{array}{l}1.051 \\
(0.734\end{array}$ & $1.505)$ & 0.7858 & $\begin{array}{l}\text { HBV } \\
\text { infec }\end{array}$ & & $1.053(0.805,1.3$ & 78) & 0.7059 \\
\hline & & & $>400$ & copies $/ \mathrm{m}$ & & & & APRI $\geq 0.50$ & & \\
\hline & Initial & CD4 & $\begin{array}{l}0.743 \\
(0.637\end{array}$ & $0.865)$ & 0.0006 & $\begin{array}{l}\text { Initic } \\
\text { APR }\end{array}$ & 0.5 & $\begin{array}{l}11.425 \\
(4.260,30643)\end{array}$ & & $<0.001$ \\
\hline & $\begin{array}{l}\mathrm{HBV} \\
\text { infect }\end{array}$ & & $\begin{array}{l}1.432 \\
(0.713\end{array}$ & $2.877)$ & 0.3126 & $\begin{array}{l}\text { HBI } \\
\text { infe }\end{array}$ & & $2.745(1.041,7.2$ & 43) & 0.0413 \\
\hline
\end{tabular}

Initial CD4, every 50 cells/ $\mu \mathrm{L}$ increase in the CD4 count; Duration of ART, every 1-year-increase; Initial OIs, OIs have emerged in HIV patients at the beginning of ART treatment; Classification of initial CD4/CD8 ratio, <0.3,0.3-0.5,0.5-1.0 and $>1.0$.

Approximately $1.9 \%$ of HIV/HBV patients and $1.0 \%$ of HIV patients were under LTFU or death during the course of their ART. Cox regression analysis showed that initial CD4 (HR=0.784, 95\% Cl 0.652-0.943), APRI $\geq 0.5(\mathrm{HR}=4.647,95 \% \mathrm{Cl}$ 1.331-16.227), Ols ( $\mathrm{HR}=4.910,95 \% \mathrm{Cl} 2.352-10.247)$ and age ( $\mathrm{HR}=1.336,95 \% \mathrm{Cl} 1.004-1.778)$ predicted for LTFU or death in HIV patients. Besides, HBV coinfection was no associated with increased LTFU or death $(p>0.05$, Table 4).

Table 3 Predictors of LTFU or death among HIV patients in the cox model 


\begin{tabular}{|c|c|c|}
\hline \multicolumn{3}{|c|}{ LTFU or Death } \\
\hline Variables & HR (95\% CI) & $P$ value \\
\hline Initial CD4* & $0.784(0.652,0.943)$ & 0.0098 \\
\hline Initial VL & $1.011(0.790,1.294)$ & 0.9298 \\
\hline Initial CD4/CD8 ratio & $0.254(0.030,2.164)$ & 0.2540 \\
\hline Initial APRI $\geq 0.5^{*}$ & $4.647(1.331,16.227)$ & 0.0160 \\
\hline Initial OIs* & $4.910(2.352,10.247)$ & $<0.001$ \\
\hline Duration of ART & $0.254(0.030,2.164)$ & 0.2540 \\
\hline HIV diagnosis to ART initiation interval & $1.009(0.811,1.256)$ & 0.3350 \\
\hline Age* & $1.336(1.004,1.778)$ & 0.0469 \\
\hline Gender & $2.226(0.683,7.257)$ & 0.1844 \\
\hline BMI & $0.732(0.449,1.194)$ & 0.2155 \\
\hline WHO stage & $1.279(0.778,2.104)$ & 0.3323 \\
\hline \multicolumn{3}{|l|}{ Marital status } \\
\hline Single & 1.000 & -- \\
\hline Married or lives with partner & $1.637(0.829,3.232)$ & 0.1556 \\
\hline Others & $1.423(0.437,4.642)$ & 0.5582 \\
\hline \multicolumn{3}{|l|}{ Route of HIV infection } \\
\hline MSM & 1.000 & -- \\
\hline Hetero-sexual & $1.418(0.551,3.648)$ & 0.4693 \\
\hline Others or unknown & $1.967(0.764,5.065)$ & 0.1610 \\
\hline \multicolumn{3}{|l|}{ ART regimen } \\
\hline TDF & 1.000 & -- \\
\hline Second-line ART(LPV/r) & $1.781(0.871,3.644)$ & 0.1139 \\
\hline Others & $0.702(0.096,5.118)$ & 0.7266 \\
\hline HBV co-infection & $1.735(0.898,3.352)$ & 0.1012 \\
\hline
\end{tabular}

Age, every 10-year-increase; * refers to $p$ value significant $(p<0.05)$.

\section{Discussion}

In our study, $841 \mathrm{HIV} / \mathrm{HBV}$ co-infected patients (the prevalence rate was 4.3\% among HIV-infected patients receiving ART) received ART for an average of 34.5 months, about $93.2 \%$ of them took drugs on time and the LTFU rate was $1.2 \%$. The mortality rate of HIV/HBV co-infected patients was $0.5 \%$, which was significantly lower than that of other studies (19.0\%) $[4,21,28]$. We observed that HIV diagnosis to ART initiation interval, the initial incidence of Ols (9.3\%) and baseline clinical characteristics ALT, AST for HIV/HBV co-infected patients were higher than those of HIV monoinfected patients. Moreover, baseline CD4 count, CD4/CD8 ratio, platelet and hemoglobin were lower in these patients. And, HBV coinfection affects the incidence of $A P R I \geq 0.5$, but does not affect the incidence of CD4<200 cells/ $\mu \mathrm{L}$, CD4/CD8 ratio $<0.30$ and VL $>400$ copies/mL in HIV patients after the ART (Table 2).

After adjusting the effect of baseline CD4 count on indicator changes during ART, we found that CD 4 count was still lower in HIV/HBV co-infected patients after ART treatment, but this difference was mainly affected by baseline CD4 count (Figure $1 \mathrm{~A}$ ) and the prevalence of CD4<200 cells/ $\mu \mathrm{L}$ was also not higher than that in HIV mono-infected patients (Table 2), which further illustrated HBV co-infection does not affect the therapeutic effect of CD4 in HIV patients $[1,4]$. Further investigation demonstrated initial low CD4 count, duration of ART, initial Ols and WHO stage increased the prevalence of CD $4<200$ cells/ $\mu \mathrm{L}$ in HIV patients. Besides, initial CD4 count affects the incidence of $\mathrm{VL}>400 \mathrm{copies} / \mathrm{mL}$ and LTFU or death (HR=0.784) in HIV patients (Table 2,3). Therefore, in order to better improve the ART effect of HIV/HBV patients, we should pay attention to the impact of these baseline CD4 [44,45].

The CD4/CD8 ratio could be used by clinicians to identity patients at risk of non-AIDS-related events and higher ratio may reflect a more " normal " immune phenotype conferring enhanced prognosis and predict posttreatment control 
[46-49]. In this study, although the baseline CD4/CD8 ratio in HIV/HBV patients was lower than that in HIV monoinfected patients, there was not significant difference between the two groups patients after ART treatment. Also we found initial low CD4 count, initial low CD4/CD8 ratio, shorter duration of ART and second-line ART increased the prevalence of CD4/CD8 ratio $<0.30$ in HIV/HBV patients. Evidence have shown that initial CD4 count can affect the ratio in HIV patients [46,49-51]. Besides, $12 \%$ of HIV/HBV patients still receive CD4/CD8 ratio $<0.30$ after 34.5 months of ART.

Many studies have indicated that HIV/HBV coinfection may play a direct role in HCC, cirrhosis or liver fibrogenesis $[1,32,52,53]$, and no clear reduction in end-stage liver disease (ESLD) risk was observed over 15 years in HIV patients, even after ART treatment [54]. We can see that baseline ALT, AST and the rate of APRI $\geq 0.5$ were higher in HIV/HBV coinfected patients (Table1). During ART treatment, the ALT of HIV/HBV patients increased significantly between 0 and 3 months. And 3 months later, ALT gradually decreased and there was no difference with HIV mono-infected patients (Figure 1B). Besides, the rate of APRI $\geq 0.5$ in HIV/HBV co-infected patients was also higher, which mainly affected by initial APRI and HBV co-infection [55].In our study we also found that initital APRI $\geq 0.5$ (HR=4.6471, 95\% Cl 1.33116.227) predicted for LTFU or death in HIV patients. Some studies have shown that higher AST appear to be important mortality risk factors in HIV/HCV-coinfection [56], both AST ,ALT and APRI to predict liverrelated mortality, either alone or as components of indices of liver fibrosis [28,53,56-58]. Besides, several studies have shown a significant correlation between APRI scores and HIV viremia levels $[28,59,60]$. Therefore, the changes of AST,ALT and APRI in HIV/HBV patients after ART treatment need to be noticed, early detection of possible liver injury in patients and adjustment of ART regimens.

Currently, we can observe an increasing number of studies focused on the non-AIDS complications in HIV patients [6162], analyzing changes in biochemical indicators (e.g., cholesterol) in patients undergoing ART treatment [64,65].We found that in the course of ART treatment, the TG and TC means in HIV/HBV co-infected patients were lower than that in HIV mono-infected patients (Figure 1F-G),but the ratio of TC>5.69 mmol/L was no difference between them. HIV patients with ART are at increasing cardiovascular disease (CVD) risk and stroke, thus, the possibility to classify patients for lipid lowering treatment may be a useful tool for clinical management[66-69].But other studies showed that HIV patients with high serum total cholesterol have lower HIV RNA load and better CD4 T cell [65,70]. Therefore, there is need for prospective cohort or case control studies to determine the relationship between total cholesterol and ART outcomes in HIV patients.

Death and LTFU are the additional concerns in HIV patients [1,2,56,71,72]. With 34.5-month ART treatment, the overall mortality and loss to follow-up rate of $\operatorname{HIV}(0.3 \%$ and $0.5 \%)$ or $\mathrm{HIV} / \mathrm{HBV}(0.7 \%$ and $1.4 \%)$ patients were lower in this study. And other studies show that LTFU at 6 and 12 months compared with $9.3 \%$ and $14.4 \%[73-75]$. The main reason may be the higher ART adherence (93\%) of the HIV patients in our study. In addition to the two factors (CD4 and $A P R I \geq 0.45)$ mentioned above, we also found that intital Ols $(H R=4.910)$ and age $(H R=1.336)$ predicted for $L T F U$ or death in HIV patients. In other studies, the overall prevalence of Ols among HIV/AIDS patients on ART was 32.5-48\% [76,77], Ols that emerge very early after ART also confer an increased risk of early mortality [78].Besides, the impact of age on HIV patients has always been a topic.An exaplanation for this trend may be that older patients have poorer immunological responses than their younger counterparts [79]. Furthermore, successful ART has led to a growing number of older HIV-1-infected individuals who face both age-related and HIV-1-related inflammation, which may synergistically promote physical decline $[80,81]$. We also found that HBV co-infection had no effect on HIV patients' loss of follow-up or death $[4,32,56]$.

Limitations of this study were also considered. Indeed, due to individual differences, it is impossible to collect timely drug replacement information of patients, so we analyzed the ART treatment of HIV/HBV patients as a whole. 
Additionally, laboratory examination of HIV patients could not guarantee that they would be checked during each follow-up. Finally, there are few data on mortality in HIV/HBV patients in this study. Further long-term study are needed about the ART effect of HIV/HBV disease progression.

In this cohort analysis of HIV/HBV co-infected patients on ART outcomes, we found that clinical indicators such as CD4 count, VL, CD4/CD8 ratio, AST, the prevalence of Ols and APRI $\geq 0.5$ were improved significantly over time on ART treatment. However, the abnormal rate of AST and APRI was higher in HIV/HBV patients, and CD4, TC and TG were lower than those in HIV patients. HBV co-infection affect the prevalence of $A P R I \geq 0.5$, but it does not affect the abnormal incidence of other clinical indicators in HIV patients. Besides, initial CD4, APRI $\geq 0.5$ initial Ols status and age had related to LTFU or death among HIV patients rather than co-infection of HBV. Further long-term studies to examine the incidence of liver injury and death outcomes in HIV/HBV patients under good ART treatment are needed in prospective studies and in larger cohorts.

\section{Declarations}

\section{Ethics approval and consent to participate}

Individual confidentiality was protected as part of the management of individual information and the processing of personal data. The study protocol and consent procedure were approved by the Institutional Review Board for Human Subject Research Centre for Public Health at Tsinghua University (Project No.: 2018022607).

\section{Consent for publication}

Not applicable

\section{Availability of data and materials}

The data that support the findings of this study are available at Beijing Center for Diseases Prevention and Control (Beijing $\mathrm{CDC}$ ) and may be obtained from the authors upon reasonable request.

\section{Competing interests}

The authors declare that they have no competing interests.

\section{Funding}

This work was supported by grant from National Natural Science Foundation of China (project no. 71874100) and Beijing Municipal Science \&Technology Commission (project no. D171100006717002).

\section{Authors' contributions}

All authors take responsibility for the structure of this paper. PW, BG and JX conducted the literature review and data analysis. PW drafted the paper. All authors contributed to the study's conception and design, interpretation of the data, and critical revisions to the paper. All authors have approved the final version for submission.

\section{Acknowledgements}

Not applicable

\section{References}


1. Hu JM, Liu KC, Luo J. HIV-HBV and HIV-HCV Coinfection and Liver Cancer Development. In:HIV/AIDSassociated Viral Oncogenesis 9E. Steven T. Rosen (Ediator).Aids-Associated Viral Oncogenes 2019.pp.231-49.

2. Singh KP, Crane M, Audsley J,et al. HIV-hepatitis B virus co-infection: epidemiology, pathogenesis, and treatment. AIDS 2017; 31:2035-52.

3. Cross TJ, Taylor CB, Harrison PM. Viral Hepatitis in HIV Infection. N Engl J Med 2007; 357:90-1.

4. Zhang F, Zhu H, Wu Y, et al. HIV, hepatitis B virus, and hepatitis $\mathrm{C}$ virus co-infection in patients in the China National Free Antiretroviral Treatment Program, 2010-12: a retrospective observational cohort study. Lancet Infect Dis $2014 ; 14: 1065-72$.

5. Badawi MM , Atif MS , Mustafa YY . Systematic review and meta-analysis of HIV, HBV and HCV infection prevalence in Sudan. Virol J 2018; 15:148.

6. Ott JJ , Stevens GA, Groeger J , et al. Global epidemiology of hepatitis B virus infection: New estimates of agespecific HBsAg seroprevalence and endemicity. Vaccine 2012; 30:2212-19.

7. Feng Dan. The Prevalence HIV/AIDS and related factors of HBV/HCV coinfection in patients in China: Systematic Review and meta-analysis. SHANXI MEDICAL UNIVERSITY

8. NCAIDS, NCSTD, China CDC. Update on the AIDS/STD epidemic in China the third quarter of 2018. Chin J AIDS STD 2018; 24:1075.

9. NCAIDS, NCSTD, China CDC. Update on the AIDS/STD epidemic in China and main response in control and prevention the second quarter. Chin J AIDS STD 2016; 22:585.

10. Alexiev I, Alexandrova M, Golkocheva-Markova E, et al. HIGH RATE OF HEPATITIS B AND C CO-INFECTIONS AMONG PEOPLE LIVING WITH HIV-1 IN BULGARIA: 2010-2014. AIDS Res Hum Retroviruses 2017; 33: 228-9.

11. Yu L, Wang J, Wangen KR, et al. Factors associated with adults' perceived need to vaccinate against hepatitis $B$ in rural China. Hum Vaccin Immunother 2016; 12:1149-54.

12. Zhang C, Zhong Y, Guo L. Strategies to prevent hepatitis B virus infection in China: Immunization, screening, and standard medical practices. Biosci Trends 2013; 7:7-12.

13. Xiao $\mathrm{M}$, Wang $\mathrm{H}$, Zhang $\mathrm{W}$, et al. Cost-effectiveness analysis of hepatitis $B$ vaccination strategy for high risk adults in Beijing. Chinese Journal of Disease Control and Prevention 2015; 19:730-4.

14. Zheng H, Wang FZ, Zhang GM , et al. An economic analysis of adult hepatitis B vaccination in China. Vaccine 2015; 33:6831-9.

15. Yang T, Chen Q, Li D,et al. High prevalence of syphilis, HBV, and HCV co-infection, and low rate of effective vaccination against hepatitis B in HIV-infected patients in West China hospital. J Med Virol 2018; 90:101-8.

16. Catherine FX, Piroth L. Hepatitis B virus vaccination in HIV-infected people: a review. Hum Vaccin Immunother 2017; 13:1-10.

17. Otto-Knapp R, Cortes CP, Saavedra F, et al. Hepatitis B prevalence and influence on HIV treatment outcome and mortality in the Chilean AIDS Cohort. Int J Infect Dis 2013;17: e919-e924.

18. Dharel N, Sterling R K. Hepatitis B Virus-HIV Coinfection: Forgotten but Not Gone. Gastroenterol Hepatol (N Y) 2014; 10:780-8.

19. Han Y, Gu L, Zhu T, et al. Emergence of lamivudine-resistant hepatitis B virus during combination antiretroviral therapy that includes lamivudine for patients co-infected with HIV and hepatitis B virus in China: a 2-year pilot cohort study. Lancet 2015; 386:S32.

20. Seremba E, Ssempijja V, Kalibbala S, et al. Hepatitis B incidence and prevention with antiretroviral therapy among HIV-positive individuals in Uganda. AIDS 2017; 31:781-6.

Page $11 / 16$ 
21. Alicia C Thornton, Sophie Jose, Sanjay Bhagani, et al. Hepatitis B, hepatitis C, and mortality among HIV-positive individuals. AIDS 2017; 31:2525-32.

22. Chloe L. Thio. Virology and clinical sequelae of drug-resistant HBV in HIV-HBV co-infected patients on HAAR Antivir Ther 2010; 15:487-91.

23. Lascar RM, Lopes AR, Gilson RJ,et al. Effect of HIV Infection and Antiretroviral Therapy on Hepatitis B Virus (HBV)-Specific T Cell Responses in Patients Who Have Resolved HBV Infection. J Infect Dis 2005; 191: $1169-79$.

24. Gatanaga H, Yasuoka A, Kikuchi Y, et al. Influence of prior HIV-1 infection on the development of chronic hepatitis B infection. Eur J Clin Microbiol Infect Dis 2000; 19:237-9.

25. Healy SA, Gupta S , Melvin AJ. HIV/HBV coinfection in children and antiviral therapy. Expert Rev Anti Infect Ther 2013; 11:251-63.

26. Sun HY, Sheng WH, Tsai MS, et al. Hepatitis B virus coinfection in human immunodeficiency virus-infected patients: A review. World J Gastroenterol 2014; 20:14598-614.

27. Nyirenda M, Beadsworth MB, Stephany $P$, et al. Prevalence of infection with hepatitis $B$ and $C$ virus and coinfection with HIV in medical inpatients in Malawi. J Infect 2008; 57:72-7.

28. Christian B, Fabian E, Macha I, et al. Hepatitis B virus coinfection is associated with high early mortality in HIVinfected Tanzanians on antiretroviral therapy. AIDS 2019; 33:465-73.

29. Ramírez-Mena A, Glass TR, Winter A, et al. Prevalence and outcomes of Hepatitis B co-infection and associated liver disease among antiretroviral therapy-naive individuals in a rural tanzanian human immunodeficiency virus cohort. Open Forum Infect Dis 2016; 3:162.

30. Iroezindu MO, Agbaji OO, Daniyam CA, et al. Liver function test abnormalities in Nigerian patients with human immunodeficiency virus and hepatitis B virus co-infection. Int J STD AIDS 2013; 24:461-7.

31. Maponga TG, Andersson MI, van Rensburg CJ, et al. HBV and HIV viral load but not microbial translocation or immune activation are associated with liver fibrosis among patients in South Africa. BMC Infect Dis 2018; 18:214.

32. Thio CL, Seaberg EC, Skolasky R Jr, et al. HIV-1, Hepatitis B virus, and risk of liver-related mortality in the Multicenter Cohort Study (MACS). Lancet 2002; 360:1921-6.

33. Rajbhandari R, Jun $\mathrm{T}$, Khalili $\mathrm{H}$,et al. HBV/HIV coinfection is associated with poorer outcomes in hospitalized patients with HBV or HIV. J Viral Hepat 2016; 23:820-9.

34. Smith CJ, Ryom L, Weber R, et al. Trends in underlying causes of death in people with HIV from 1999 to 2011 (D:A:D): a multicohort collaboration. Lancet 2014; 384:241-8.

35. Nikolopoulos GK, Paraskevis D, Psichogiou M, et al. HBV-DNA levels predict overall mortality in HIV/HBV coinfected individuals. J Med Virol 2016; 88:466-73.

36. Huang AJ, Núñez M. Outcomes in HIV/HBV-Coinfected Patients in the Tenofovir Era Are Greatly Affected by Immune Suppression. J Int Assoc Provid AIDS Care 2015; 14:360-8.

37. Hoffmann CJ, Seaberg EC, Young S, et al. Hepatitis B and long-term HIV outcomes in coinfected HAART recipients. AIDS 2009; 23:1881-9.

38. Matthews GV, Manzini P, Hu Z, et al. Impact of lamivudine on HIV and hepatitis B virus-related outcomes in $\mathrm{HIV} /$ hepatitis B virus individuals in a randomized clinical trial of antiretroviral therapy in southern Africa. AIDS $2011 ; 25: 1727-35$.

39. Nampala H, Luboobi LS, Mugisha JYT,et al. Modelling Hepatotoxicity and Antiretroviral Therapeutic effect in HIV/HBV Coinfection. Math Biosci 2018; 302:67-79.

40. Wallis CL, Godfrey C, Fitzgibbon JE, et al. Key Factors Influencing the Emergence of Human Immunodeficiency Virus Drug Resistance in Low- and Middle-Income Countries. J Infect Dis 2017; 216(suppl9):S851-S856. 
41. Su S, Fairley CK, Sasadeusz J, et al. HBV, HCV, and HBV/HCV co-infection among HIV-positive patients in Hunan province, China: Regimen selection, hepatotoxicity, and antiretroviral therapy outcome. J Med Virol 2018; 90:51825.

42. Wu S , Yan P , Yang T , et al. Epidemiological profile and risk factors of HIV and HBV/HCV co-infection in Fujian Province, southeastern China. J Med Virol 2016; 89:443-9.

43. Rena Maimaiti,Yuexin Zhang,Kejun Pan, et al. High prevalence and low cure rate of tuberculosis among patients with HIV in Xinjiang, China. Bmc Infect Dis 2017; 17:15.

44. Vinikoor MJ, Joseph J, Mwale J, et al. Age at Antiretroviral Therapy Initiation Predicts Immune Recovery, Death, and Loss to Follow-Up Among HIV-Infected Adults in Urban Zambia. AIDS Res Hum Retroviruses 2014; 30:949-55.

45. Fatukasi TV, Cole SR, Moore RD, et al. Risk factors for delayed antiretroviral therapy initiation among HIVseropositive patients. PLoS One 2017; 12:e0180843.

46. Mussini C, Lorenzini P, Cozzi-Lepri A, et al. CD4/CD8 ratio normalisation and non-AIDS-related events in individuals with HIV who achieve viral load suppression with antiretroviral therapy: an observational cohort study. Lancet HIV 2015; 2:e98-e106.

47. Castilho JL, Shepherd BE, Koethe J, et al. CD4+/CD8+ ratio, age, and risk of serious noncommunicable diseases in HIV-infected adults on antiretroviral therapy. AIDS, 2016, 30(6):899-908.

48. Thornhill J, Inshaw J, Oomeer S, et al. Enhanced normalisation of CD4/CD8 ratio with earlier antiretroviral therapy at Primary HIV Infection. J Acquir Immune Defic Syndr 2016; 73:69-73.

49. Davy-Mendez T, Napravnik S, Zakharova O, et al. Acute HIV Infection and CD4/CD8 Ratio Normalization after Antiretroviral Therapy Initiation. J Acquir Immune Defic Syndr 2018;79:510-9.

50. Tinago W, Coghlan E, Macken A, et al. Clinical, Immunological and Treatment-Related Factors Associated with Normalised CD4+/CD8+ T-Cell Ratio: Effect of Naïve and Memory T-Cell Subsets. PLoS One 2014; 9:e97011.

51. Hughes RA, May MT, Tilling K, et al. Long terms trends in CD4+ cell counts, CD8+ cell counts, and the CD4+: CD8+ ratio. AIDS 2018; 32:1361-7.

52. Boyd A, Bottero J, Miailhes P, et al. Liver fibrosis regression and progression during controlled hepatitis B virus infection among HIV-HBV patients treated with tenofovir disoproxil fumarate in France: a prospective cohort study. J Int AIDS Soc 2017; 20:21426.

53. Re V L, Newcomb C W, Carbonari D M, et al. Determinants of Liver Complications Among HIV/Hepatitis B VirusCoinfected Patients. JAIDS 2019;82(1):71-80.

54. Klein MB, Althoff KN, Jing Y, et al. Risk of End-Stage Liver Disease in HIV-Viral Hepatitis Coinfected Persons in North America From the Early to Modern Antiretroviral Therapy Eras. Clin Infect Dis 2016; 63:1160-7.

55. Price JC, Seaberg EC, Stosor V, et al. AST-to-platelet ratio index increases significantly 3 years prior to liver-related death in HIV-hepatitis-coinfected men. AIDS, 2018 32(17):1.

56. Scherzer R, Heymsfield SB, Rimland D, et al. Association of serum albumin and aspartate transaminase with 5year all-cause mortality in HIV/hepatitis C virus coinfection and HIV monoinfection. AIDS 2017; 31:71-9.

57. Vinikoor MJ, Sinkala E, Mweemba A, et al. Elevated AST-to-platelet ratio index is associated with increased allcause mortality among HIV-infected adults in Zambia. Liver Int 2015; 35:1886-92.

58. Osakunor DN, Obirikorang C, Fianu V, et al. Hepatic Enzyme Alterations in HIV Patients on Antiretroviral Therapy: A Case-Control Study in a Hospital Setting in Ghana. PLOS ONE 2015; 10:e0134449.

59. Hawkins C, Christian B, Fabian E, et al. HIV/HBV co-infection is a significant risk factor for liver fibrosis in Tanzanian HIV-infected adults. JAIDS 2017; 76:298-302. 
60. DallaPiazza M, Amorosa VK, Localio R, et al. Prevalence and risk factors for significant liver fibrosis among HIVmonoinfected patients. BMC Infect Dis 2010; 10:116.

61. Ford N, Shubber Z, Meintjes G, et al. Causes of hospital admission among people living with HIV worldwide: a systematic review and meta-analysis. Lancet Hiv 2015; 2:e438-e444.

62. Mosepele M, Molefe-Baikai OJ, Grinspoon SK, et al. Benefits and Risks of Statin Therapy in the HIV-Infected Population. Curr Infect Dis Rep 2018; 20:20-8.

63. ADVICE study group. Vorapaxar for HIV-associated inflammation and coagulopathy (ADVICE): a randomised, double-blind, placebo-controlled trial. Lancet HIV 2018; 5:e553-e559.

64. Askgaard G, Kristoffersen US, Mehlsen J, et al. Decreased Heart Rate Variability in HIV Positive Patients Receiving Antiretroviral Therapy: Importance of Blood Glucose and Cholesterol. PLoS ONE 2011; 6:e20196.

65. Melaku Adal, Rawleigh Howe, Desta Kassa, et al. Associations of gender and serum total cholesterol with CD4+ T cell count and HIV RNA load in antiretroviral-naive individuals in Addis Ababa. BMC Public Health 2018; 18:94353.

66. Rodríguez-Gallego E, Gómez J, Domingo P, et al. Circulating metabolomic profile can predict dyslipidemia in HIV patients undergoing antiretroviral therapy. Atherosclerosis 2018 ;273:28-36.

67. Benjamin LA, Corbett EL, Connor MD, et al. HIV, antiretroviral treatment, hypertension, and stroke in Malawian adults: A case-control study. Neurology 2016; 86:324-33.

68. Egaña-Gorroño L, Martínez E, Cormand B,et al. Impact of genetic factors on dyslipidemia in HIV-infected patients starting antiretroviral therapy. AIDS 2013; 27:529-38.

69. Sekai C. Mathabire Rücker, Tayea A , Bitilinyubangoh J ,et al. High rates of hypertension, diabetes, elevated lowdensity lipoprotein cholesterol, and cardiovascular disease risk factors in HIV-infected patients in Malawi. AIDS 2018; 32:253-60.

70. Míguez MJ, Lewis JE, Bryant VE, et al. Low cholesterol? Don't brag yet. hypocholesterolemia blunts HAART effectiveness: a longitudinal study. J Int AIDS Soc 2010; 13:25.

71. Arnesen R, Moll AP, Shenoi SV. Predictors of loss to follow-up among patients on ART at a rural hospital in KwaZulu-Natal, South Africa. PLoS One 2017; 12:e0177168.

72. Grimsrud A, Balkan S, Casas EC, et al. Outcomes of antiretroviral therapy over a 10-year period of expansion: a multicohort analysis of African and Asian HIV programs. J Acquir Immune Defic Syndr 2014; 67:e55-66.

73. Grimsrud AT, Cornell M, Egger M, et al. Impact of definitions of loss to follow-up (LTFU) in antiretroviral therapy program evaluation: variation in the definition can have an appreciable impact on estimated proportions of LTFU. J Clin Epidemiol 2013; 66:1006-13.

74. Gezae KE, Abebe HT, Gebretsadik LG. Incidence and predictors of LTFU among adults with TB/HIV co-infection in two governmental hospitals, Mekelle, Ethiopia, 2009-2016: survival model approach. BMC Infect Dis 2019; 19:107.

75. Guy R, Wand H, McManus H, et al. Antiretroviral treatment interruption and loss to follow-up in two HIV cohorts in Australia and Asia: implications for 'test and treat' prevention strategy. AIDS Patient Care STDS 2013; 27:681-91.

76. Mitiku H, Weldegebreal F, Teklemariam Z. Magnitude of opportunistic infections and associated factors in HIVinfected adults on antiretroviral therapy in eastern HIV AIDS (Auckl) 2015; 7:137-44.

77. Bisson GP1, Ramchandani R, Miyahara S, et al. Risk factors for early mortality on antiretroviral therapy in advanced HIV-infected adults. AIDS 2017; 31:2217-25.

78. Siddiqi OK, Elafros MA, Bositis CM, et al. New-onset seizure in HIV-infected adult Zambians: A search for causes and consequences. Neurology 2017; 88:477-82.

Page 14/16 
79. Hinkin $\mathrm{CH}, \mathrm{Hardy} \mathrm{DJ}$, Mason $\mathrm{KI}$, et al. Medication adherence in HIV-infected adults: effect of patient age, cognitive status, and substance abuse. AIDS 2004; 1:S19-25.

80. The Lancet Hiv. Preparing for an ageing HIV epidemic. Lancet HIV 2017; 4:e277.

81. Ingle SM, May MT, Gill MJ, et al. Impact of risk factors for specific causes of death in the first and subsequent years of antiretroviral therapy among HIV-infected patients. Clin Infect Dis 2014; 59:287-97.

\section{Figures}
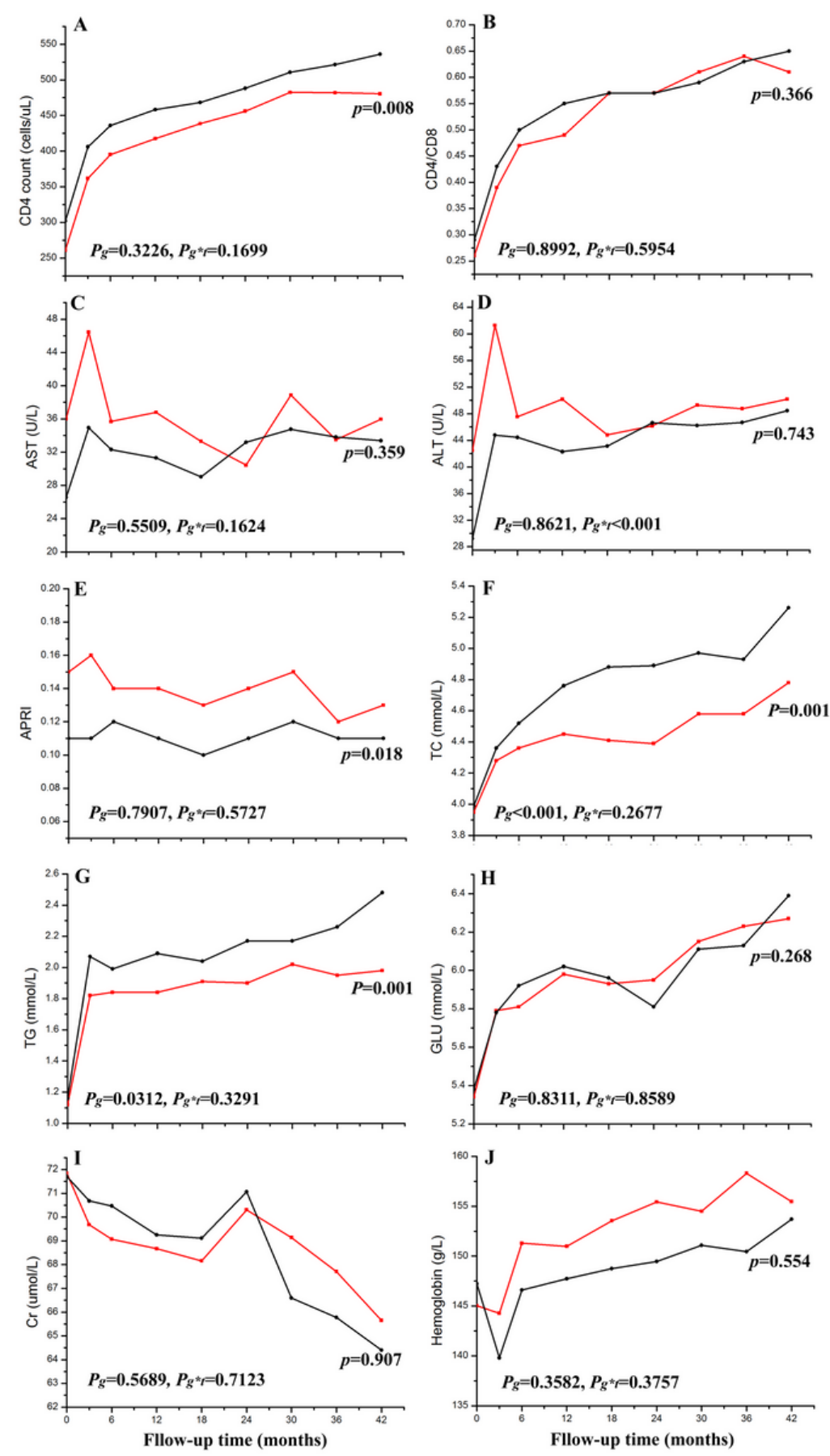

Figure 1 
The tendency chart of main clinical indicators.Red line,HIV/HBV co-infected patients;black line,HIV mono-infected patients. pg, the rapeutic effect analysis of HIV and HIV/HBV patients after correction of baseline data; pg*t, the interaction between therapeutic effect and time effects; $p$, comparisons of two groups after 42 months of ART treatment.

\section{Supplementary Files}

This is a list of supplementary files associated with this preprint. Click to download.

- Additionalfile1.docx 